\title{
Nitrate Adsorption by Activated Carbon
}

\author{
Adam Rosenblum \\ Herbert Wertheim College of Engineering
}

Faculty Mentor: David Mazyck, Department of Environmental Engineering Sciences

\begin{abstract}
Activated carbon is a type of carbon and is a known catalyst for a variety of chemical reactions. Uses of activated carbon include purifying liquids and gases, food and beverage processing, odor removal, industrial pollution control, and numerous other applications. There are a variety of different activated carbons, with most being derived from coal, peat, and wood. Activated carbon is a great catalyst because the surface area and the availability of small pores facilitate adsorption and makes chemical reactions better. One primary use of activated carbon is its adsorption of nitrates onto its surface. This paper delves into different adsorption rates of an activated carbon (Filtrasorb 600) that is treated with different chemicals and then subjected to a chemical activation at a constant pressure under different gaseous conditions. Data collected during experiments indicate there are significant results between surface functional groups and nitrate percentage removal during adsorption.

Keywords: activated carbon, adsorption, nitrates
\end{abstract}

\section{Introduction}

Although nitrates are an essential component in the biological world, excessive exposure to nitrates poses severe risks to humans and the environment. In the environment, nitrates have an effect on water quality. In water, excessive nitrates cause algae to grow to the point where oxygen levels are reduced for fish and cause them to die. Drinking water contatning nitrate also poses health risks to humans. Nitrate is especially harmful to babies if consumed and can cause methemoglobinemia (blue baby syndrome). In adults, effects of nitrate include increased heart rate, nausea, headaches, cramps, and increased cancer risks (Minnesota Department of Health, 2019). It is imperative that excessive nitrates are removed from processes to avoid the health risks. Carbons can be treated by acids, bases, or oxidizing agents to produce favorable chemical and physical properties for different applications (Chen, Wu, 2004). Physical properties of carbons include their specific surface area, size, and porosity, whereas chemical properties are mainly determined by their surface functional groups, including carboxyls, carboxylic anhydrides, phenols, lactones, lactols, carbonyls, quinones, and quinone- like structures (Boehm, 1994). Pure carbon surfaces do not always carry all these functional groups, but are often 
introduced through chemical processes to enhance the adsorption properties. Oxidation of activated carbons by a $\mathrm{H}_{2} \mathrm{O}_{2}$ solution increases hydroxide groups when the solution $\mathrm{pH}$ is not controlled (Chen, $\mathrm{Wu}, 2004)$. Oxidation of activated carbons by a hydrogen peroxide solution increases hydroxide groups when the solution $\mathrm{pH}$ is not controlled (Gomez-Serrano, AcedoRamos, et al., 1994) and nitric acid treatment increases the quantity of acidic surface functional groups, such as nitro groups (Noh, Schwarz, 1990). $\mathrm{HNO}_{3}$ treatment increases the quantity of acidic surface functional groups (Chen, Wu, 2004). Though different treatments using acids and bases, the size, surface area, porosity, and functional groups of the carbon can be altered. Porosity is known to be a huge contributor to the adsorption process, but many studies have been done to analyze other causes like surface chemistry. It was found that not only porosity but also surface chemistry plays an important role in the adsorption process (Nielsen, Biggs, et al., 2014). The different functional groups on the surface of different carbons play an important role in the adsorption process, and if they are treated with different acids and bases these functional groups have numerous organic interactions with the substance they are adsorbing.

There is still much room to be developed to increase adsorption capacity of activated carbons (Ota et al., 2013) for ionic pollutants such as heavy metals (Sato et al., 2007) and nitrate/nitrite (Mizuta et al., 2004). Although removal of nitrate and nitrite can be conducted by ion exchange, reverse osmosis, biological and chemical reductions (Fanning, 2000) etc., adsorptive removal is one of the most attractive options among them from the point of operation cost (Ota et al., 2013). Activated carbon has been used for nitrate removal throughout its scientific history, however there is an abundant amount of work to be done to increase activated carbons efficiency in removing nitrates. The rationale for determining more knowledge about how nitrates and functional groups on the surface of activated carbons interact is because it is one of the cheaper options for nitrate removal.

This research paper focuses on the different chemical interactions between Filtrasorb 600 that is treated with acids and bases and a nitrate stock solution. Utilizing values such as porosity, surface area, $\mathrm{pH}, \mathrm{ORP}$, and the nitrate percent removal the paper is able to discuss how certain functional groups of Filtrasorb 600 and nitrates interact in a gaseous environment. 


\section{Materials}

\section{Chemicals}

The chemicals used in this research project were citric acid, potassium carbonate, nitric acid, and hydrogen peroxide. The citric acid and potassium carbonate were diluted to $1 \mathrm{M}$, the hydrogen peroxide and nitric acid were diluted to 5M and 10M nitric acid samples. Stock solutions were made with sodium nitrate. Dilutions and stock solutions were all made with deionized water.

\section{Adsorbents}

The adsorbent used in the experiments conducted was Filtrasorb 600, also abbreviated as F600.

\section{Methods}

\section{Physical Activations}

The F600 carbon was activated in the furnace at $900^{\circ} \mathrm{C}$. The activated $\mathrm{F} 600$ was added to solutions of $1 \mathrm{M}$ citric acid, $1 \mathrm{M}$ potassium carbonate, $5 \mathrm{M}$ nitric acid, $10 \mathrm{M}$ nitric acid, and 5M hydrogen peroxide in a 1:10 ratio. The solutions were stirred for one hour and vacuum filtered with a $0.45 \mu \mathrm{m}$ nitrocellulose filter. The carbon was rinsed with deionized water until a constant $\mathrm{pH}$ of the rinsate was achieved and dried in a $150^{\circ} \mathrm{C}$ oven. The $\mathrm{pH}$ 's of each sample varied, but were taken until consant. For instance the $5 \mathrm{M}$ nitric acids $\mathrm{pH}$ leveled out at about 2, but the $1 \mathrm{M}$ citric acid leveled out more near 5.

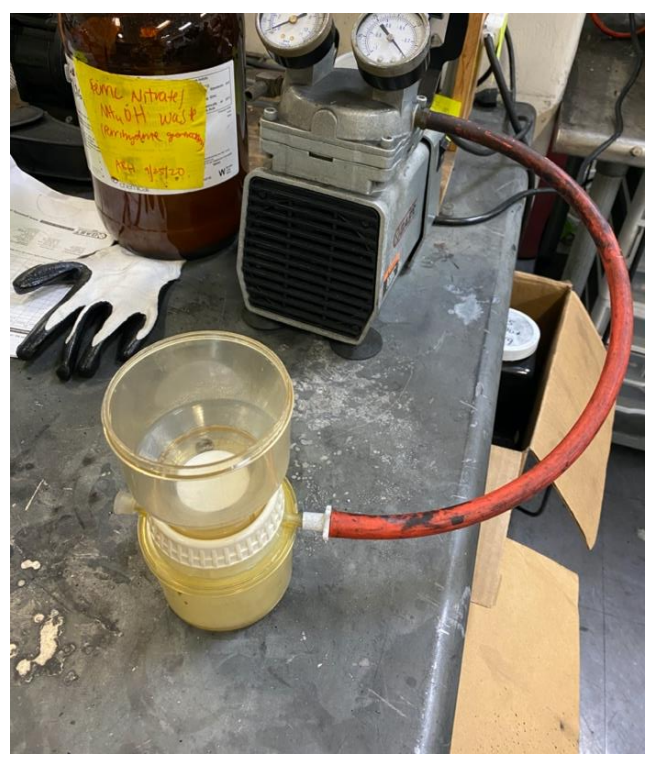

Figure 1. Vacuum Filtration Setup 


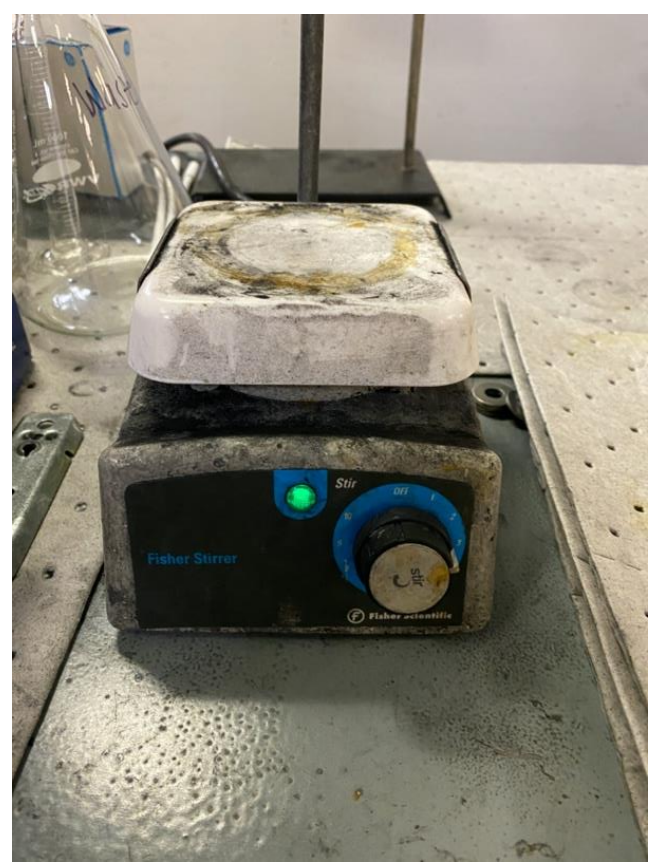

Figure 2. Stir Plate

\section{Chemical Activations}

The F600 carbon varieties were stirred in a pressure vessel with a $10 \mathrm{mg} \mathrm{NO}_{3}{ }^{-} / \mathrm{L}$ stock solution and treated with air, oxygen, argon, and nitrogen for 30 minutes. Separate samples of each carbon were treated with each gas. For example, 1 gram of the $5 \mathrm{M}$ nitric acid rinsed carbon was treated with air, and then 1 gram with oxygen, etc. Each activation had $100 \mathrm{~mL}$ of stock solution and 1 gram of carbon added. After 30 minutes of stirring at $20 \mathrm{psi}, 20 \mathrm{~mL}$ of the solution was filtered through a $0.45 \mu \mathrm{m}$ syringe and the $\mathrm{pH}$ and ORP were measured. $\mathrm{An} \mathrm{NO}_{3}{ }^{-}-\mathrm{N}$ Hach test in a Hach DR6000 spectrophotometer for nitrate concentration was conducted. Blanks were also taken for each gas with the $10 \mathrm{mg} \mathrm{NO}_{3}{ }^{-} / \mathrm{L}$ stock solution.

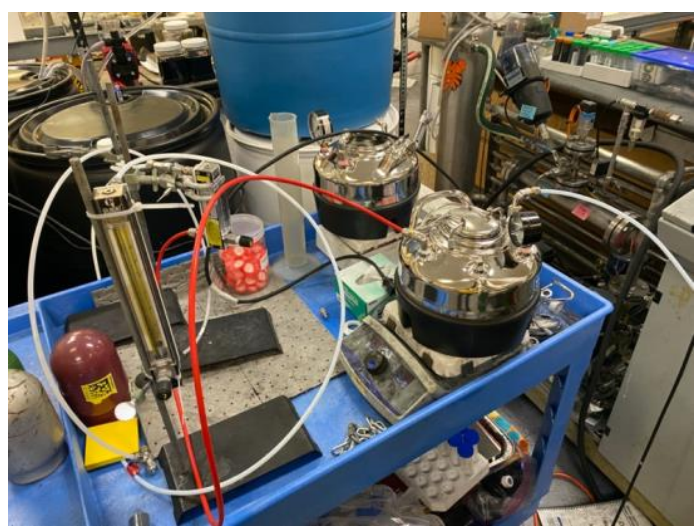

Figure 3. Pressure Vessel Setup for Chemical Activations 


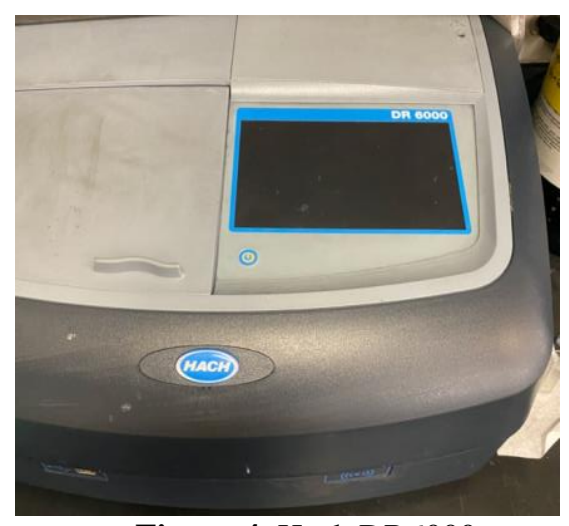

Figure 4. Hach DR6000

\section{Contact pH}

In order to determine the contact $\mathrm{pH}$ of the carbon varieties, the different rinsed carbon samples were added to deionized water in a 1:10 ratio (carbon to water) and stirred for thirty minutes. After this, the $\mathrm{pH}$ was taken with a $\mathrm{pH}$ probe.

\section{Results}

Table 1. Pore Sizes of Different Rinsed F600 Carbons

\begin{tabular}{cccccc}
\hline Sample & BET $\left(\mathrm{m}^{2} / \mathrm{g}\right)$ & Pore Size $(\AA)$ & $\begin{array}{c}\text { Cum Pore Vol. } \\
(\mathrm{cc} / \mathrm{g})\end{array}$ & $\begin{array}{c}\text { BJH Pore } \\
\text { Vol. }(\mathrm{cc} / \mathrm{g})\end{array}$ & $\begin{array}{c}\text { Cum Micropore } \\
\text { Vol. }(\mathrm{cc} / \mathrm{g})\end{array}$ \\
\hline $1 \mathrm{M} \mathrm{C}_{6} \mathrm{H}_{8} \mathrm{O}_{7}$ & 637 & 21.17 & 0.3372 & 0.07346 & 0.2169 \\
$5 \mathrm{M} \mathrm{H}_{2} \mathrm{O}_{2}$ & 832 & 20.33 & 0.4234 & 0.08121 & 0.2900 \\
$5 \mathrm{M} \mathrm{HNO}_{3}$ & 809 & 20.48 & 0.4142 & 0.07741 & 0.2832 \\
$10 \mathrm{M} \mathrm{HNO}_{3}$ & 805 & 19.96 & 0.4014 & 0.07336 & 0.2816 \\
\hline
\end{tabular}

*BET: Brunauer-Emmett-Teller Surface Area Analysis

*BJH: Barrett-Joyner-Halenda Pore Size and Volume Analysis 


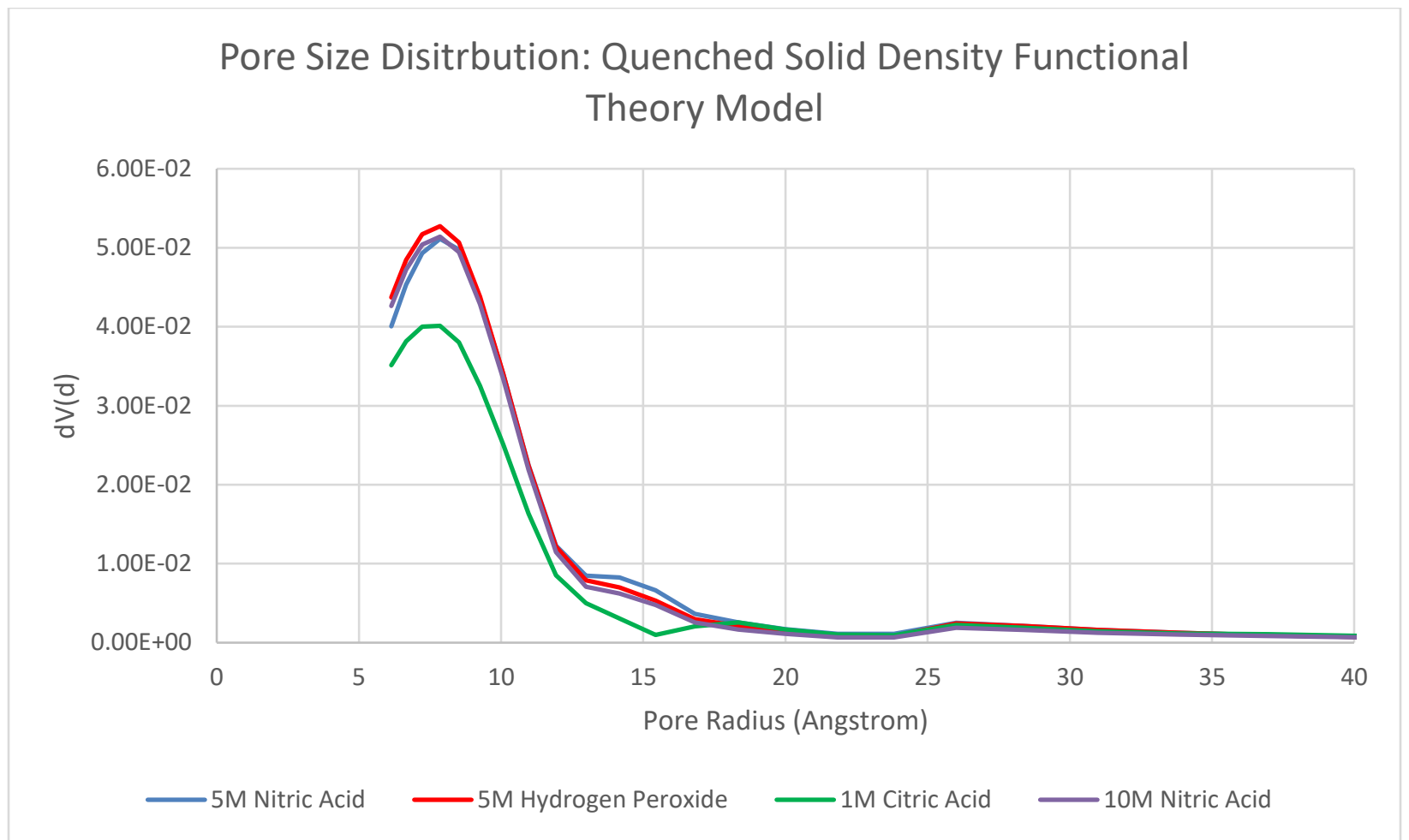

Figure 5. Pore Size Distribution of Each Rinsed Carbon

Porosity is one of the main attributes of activated carbon that influences adsorption. As displayed in Table 1, the $1 \mathrm{M}$ citric acid treated carbon had the smallest surface area with the Brunauer-Emmett-Teller method, but the largest pore size of all the carbons. It also has the smallest pore volumes with the three different pore volume measurements. For every carbon, as the BET surface area increased, the pore volume also increased. The average pore size of the rinsed carbons was 20.49 angstroms ranging between 19.96 and 21.17 so they were close in deviation. In Figure 5, it is evident that the 5M hydrogen peroxide had the highest differential pore size distribution. The $10 \mathrm{M}$ nitric acid and the $5 \mathrm{M}$ nitric acid are close behind the hydrogen peroxide, with a distinct difference between diffential pore size displayed with the $1 \mathrm{M}$ citric acid. 


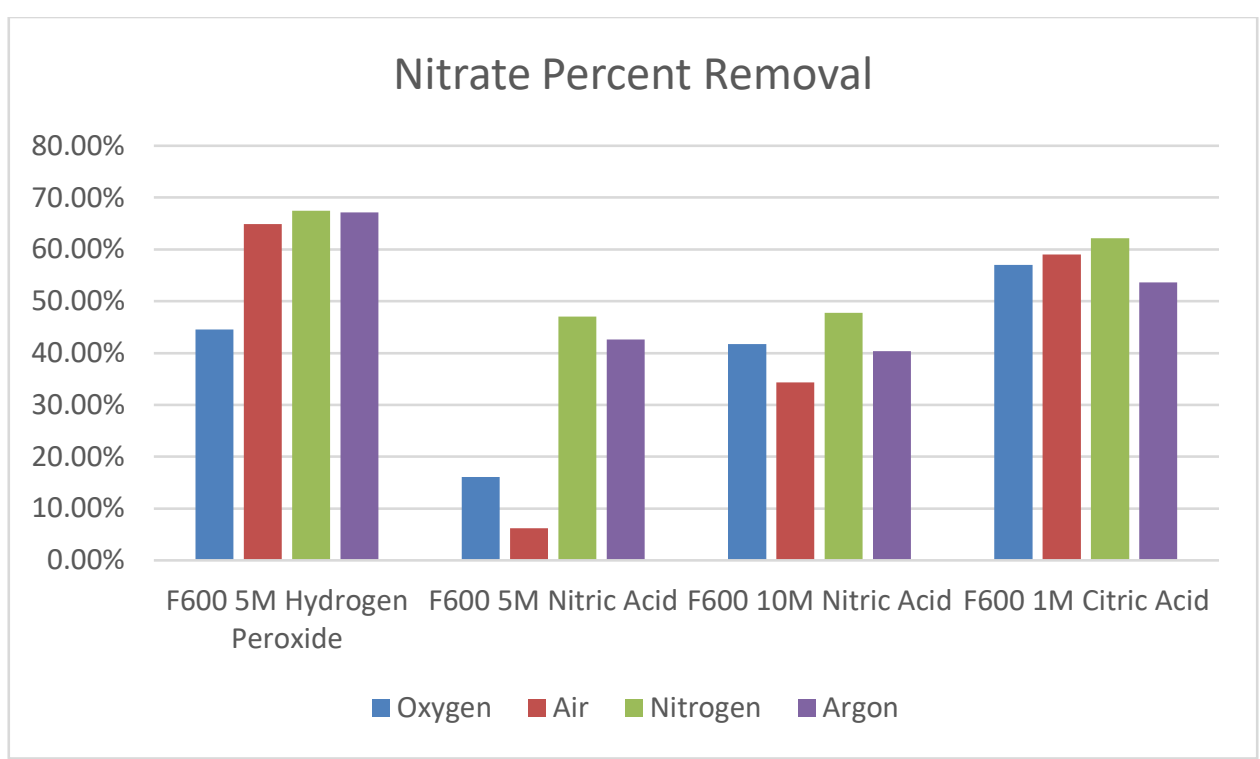

Figure 6. Graph showing the percent removal of nitrate with each gas per carbon

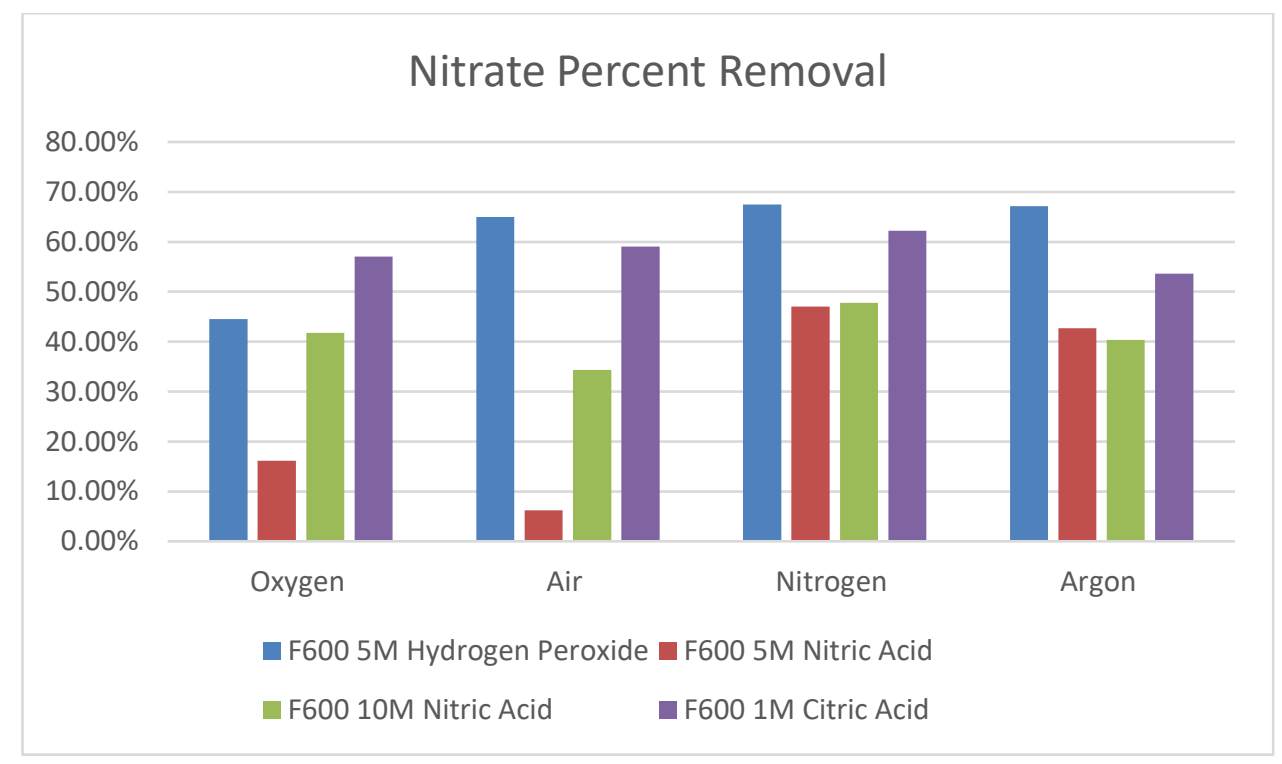

Figure 7. Graph showing the percent removal of nitrate on each carbon per gas

The carbons were treated in different gaseous environments to see which cases had the most nitrate removal. The graphs above illustrate the nitrate percent removal per carbon and per gas. In Figure 6, it is clear the 5M hydrogen peroxide rinsed F600 had the highest nitrate percent removal with an exception to oxygen. On average, the 1M citric acid treated F600 had the most nitrate percent removal. In Figure 7, it is clear the nitrogen environment contributed to the most nitrate percent removal and the argon environment was a close second. In the case of oxygen and 
air, the oxygen had a higher nitrate percent removal for the nitric acid treated F600, and the air had a higher nitrate percent removal for the citric acid and hydrogen peroxide.

\section{Discussion}

In Figure 6, the $1 \mathrm{M}$ citric acid rinsed carbon and 5M hydrogen peroxide rinsed carbon have the highest nitrate percent removal. The functional groups on the carbon surfaces can have effects on the amount of nitrate removal. The treatment of carbons by citric acid, nitric acid, and hydrogen peroxide can also effect the surface area of carbons. There is a possible increase in the carbons surface area when treated with nitric acid (Gomez-Serrano, Acedo-Ramos, et al., 1997). However, this is not a significant increase because simple inorganic acids (nitric acid) have small molecular weights and cannot be adsorbed by organic functional groups in carbons. On the other hand, organic acids such as citric acid can be adsorbed by activated carbons during the surface modification (Chen, $\mathrm{Wu}, 2004$ ). In the BET porosity data, there is a $20 \%$ decrease in the $1 \mathrm{M}$ citric acid rinsed carbon when compared to the $10 \mathrm{M}$ nitric acid carbon. However, the $1 \mathrm{M}$ citric acid rinsed carbon still had the second most nitrate removal when treated with nitrogen, argon, and air and the most nitrate removal with oxygen of any of the carbons. This point is intriguing because the $1 \mathrm{M}$ citric acid rinsed carbon had the lowest surface area and pore volume, but the largest pore size. From these results, it is evident that a stronger base like hydrogen peroxide and weaker acids like citric acid have a higher nitrate percent removal than stronger acids. An additional note worth pointing out is the $5 \mathrm{M}$ nitric acid rinsed carbon had a significantly less nitrate percent removal than the 10M nitric acid rinsed carbon when treated with oxygen and air. This could indicate that molarity of strong acids has an effect on nitrate percent removal of carbons. Oxygen and air may interact differently with functional groups on the surface of nitric acid rinsed carbons depending on their concentrations.

\section{Acknowledgements}

I would like to acknowledge Michelle Finn for her constant support and guidance throughout the duration of my research. Finally, I would like to acknowledge the University Scholars Program for providing the funding to partake in this research opportunity. 


\section{References}

Boehm, H. P. (1994). Some aspects of the surface chemistry of carbon blacks and other carbons. Carbon, 32(5), 759-769.

Chen, J. P., \& Wu, S. (2004). Acid/base-treated activated carbons: characterization of functional groups and metal adsorptive properties. Langmuir, 20(6), 2233-2242.

Fanning, J. C. (2000). The chemical reduction of nitrate in aqueous solution. Coordination Chemistry Reviews, 199(1), 159-179.

Gómez-Serrano, V., Acedo-Ramos, M., López-Peinado, A. J., \& Valenzuela-Calahorro, C. (1994). Oxidation of activated carbon by hydrogen peroxide. Study of surface functional groups by FTir. Fuel, 73(3), 387-395.

Gomez-Serrano, V., Acedo-Ramos, M., Lopez-Peinado, A. J., \& Valenzuela-Calahorro, C. (1997). Mass and surface changes of activated carbon treated with nitric acid. Thermal behavior of the samples. Thermochimica acta, 291(1-2), 109-115.

Minnesota Department of Health. (2019). Nitrate in Drinking Water. Minnesota Depratment of Health.

Mizuta, K., Matsumoto, T., Hatate, Y., Nishihara, K., \& Nakanishi, T. (2004). Removal of nitratenitrogen from drinking water using bamboo powder charcoal. Bioresource technology, 95(3), 255-257.

Nielsen, L., Biggs, M. J., Skinner, W., \& Bandosz, T. J. (2014). The effects of activated carbon surface features on the reactive adsorption of carbamazepine and sulfamethoxazole. Carbon, 80, 419-432.

Noh, J. S., \& Schwarz, J. A. (1990). Effect of HNO3 treatment on the surface acidity of activated carbons. Carbon, 28(5), 675-682.

Ota, K., Amano, Y., Aikawa, M., \& Machida, M. (2013). Removal of nitrate ions from water by activated carbons (ACs) - influence of surface chemistry of ACs and coexisting chloride and sulfate ions. Applied surface science, 276, 838-842.

Öztürk, N., \& Bektaş, T. E. (2004). Nitrate removal from aqueous solution by adsorption onto various materials. Journal of hazardous materials, 112(1-2), 155-162.

Sato, S., Yoshihara, K., Moriyama, K., Machida, M., \& Tatsumoto, H. (2007). Influence of activated carbon surface acidity on adsorption of heavy metal ions and aromatics from aqueous solution. Applied Surface Science, 253(20), 8554-8559. 